https://doi.org/10.15407/fd2021.04.153

UDC 123.1

Anna LAKTIONOVA, Doctor of Science in Philosophy,

Professor at the Department of Theoretical and Practical Philosophy, Faculty of Philosophy, Taras Shevchenko National University of Kyiv, 01601, Kyiv, Volodymyrska St., 64/13

laktionovaanna@yahoo.com

https://orcid.org/0000-0001-8236-7217

\title{
WILL AND VOLITION: PERSONAL CONDITIONS OF POSSIBILITY OF BEING AN AGENT
}

Will is a very old important philosophical concept, an analysis of which is very specific, if not odd, comparatively with the others (when it fruitfully proceeds in terms of criteria). This concept ('will') is going to be used to provide and clarify conditions of possibility for person of being an agent. In doing that I refer to the correspondent pieces of Wittgenstein's Tractatus and Philosophical Investigations; and to their interpretations by M. Alvarez in "Wittgenstein on Action and Will" (2009) and D. K. Levy in "Morality without Agency" (2017). Person is essentially constituted by 'powerless' will in terms of 'understanding' that is experienced during her life. Action depends on and manifests understanding by will of a personal attitude to some states of affairs. Will does not incline a person to particular desires about preferable states of affairs or actions. Will is not about states of affairs. By willing I value the world, its portions, they appear significant, important to me. Volition is treated as related to will. Both are personal conditions of being an agent with priority of agency as capacity realized by rational actions.

Keywords: will, volition, agency, rationality, normativity.

Agency is a specific human capacity of being able to act. Agency as such capacity is realized in agent's actions. Actions evidence realization of this capacity. Agency is crucial root for agent's actions. Admitting agency as proper capacity of an agent commits to ascribe him freedom of will and personal identity. Human agency involves psychological, ethical, intellectual, and physical aspects or modes for interpreting this capacity. Mentioned modes are not to be separated, but rather functionally integrated in agency. John Hyman [Hyman, 2015] gives an interesting treating of the mentioned issues which became a subject of different reactions nowadays. My analysis of the topic is also involving the concept of rationality, as a paradoxical criterion of what and how is being performed in human actions.

Цитування: Laktionova, A. (2021). Will and volition: personal conditions of possibility of being an agent. Філософська думка, 4, 153-162. https://doi.org/10.15407/fd2021.04.153 
A standard approach to agency and actions takes intention as a key human state, the content of intention is treated in terms of reasons (if not causes) of actions. But the mental state of intention, of intending something, is not a direct realization of agency as human capacity. Further, intention is seen dependent on other mental attitudes, at least belief and desire. Agency is realized in actions. If intention is a reason for action, agency loses its priority role for the explanation of action; we even don't need an agent, it's not an agent, but mental state of intention that causes action. At the same time agency as potential capacity needs some stimulus to be realized. Intention does not seem to be appropriate candidate for the role of such stimulus. Even more, it might be that we exaggerate our experiencing such attitude or state as intention; we rather seldom experience intention than we are used to think.

Agent acts, performs actions due to inherent by him agency and freedom of will. Being the same agent who performs different actions witnesses personal identity of an agent (he remains to be the same human being nevertheless that his mental and physical features can change through time of his life, he acknowledges himself to be himself during his life). Will, volition, freedom, as well as notions of action, conduct, behavior sound very synonymous in everyday usage.

To be free to will and, consequently to act, initiates realization of agent's agency in his actions. Acting voluntarily is a better way to clarify realization of agency than relying on intentions as reasons for actions. Voluntary action does not compulsory need any reason. But being free to act involves psychological, ethical, intellectual, and physical aspects essentially committing if we accept attempt to explain agency and actions in terms of realized in actions agency (stimulated by free will of agent).

Actions are voluntary if there were not external compulsion to perform an act or agent's ignorance about what is he performing (or both). Compulsion is an ethical issue; ignorance is an epistemological issue. Compulsion blocks agent's will, desire, making choice to perform an action. Ignorance blocks agent's being aware of what and why he is doing. One can be ignorant about compulsion and one can be ignoring (unaware) of his being externally obliged not to know about his actions. Such actions are involuntary. Thus, it seems that an agent can lose his volition, power to will and act, but still act. That sounds paradoxical or even contradictory. It seems that evaluation of such actions in terms of rationality (being reasonable and optimally effective) is impossible.

Another side of just mentioned is to ask whether the voluntariness and involuntariness exclude each other. We tend to treat as voluntary an action that accords to our mental attitudes, and as involuntary when it disaccords them. But disaccording some attitudes is still experienced as some opposite mental attitudes (desire - not desire (disgust), belief - disbelief etc.). So, involuntariness can be seen as a special case of negative, but still voluntariness. In this sense all actions are voluntary. Voluntariness can come in degrees and is not vanished by being negative. Even involuntariness, negative voluntariness does not indicate ceasing of agent's 
volition. This idea corresponds to the introductory remarks about agent's freedom of will and to will.

It is rational for an agent to act reasonably and effectively optimally according to his actually experienced attitudes. Attitudes can come in degree. Rationality can come in degree, but paradoxically does not have its opposite. We can speak about mistaken rationality, not sufficient rationality. Even when we speak about irrationality, we take it as quasi-rationality, as not understandable yet, but available alternative rationality. Attitude concerning something can be absent. Agent can feel apathy, be neutral, indifferent, about something. Absence of attitude is absence of certain positive or negative concern about something, but not of possibility that such concern can appear as actual for an agent. Will and volition are closely related concepts. Will involves power and is rather capacity; volition is directed on something, is general ability to attitudinize. In case of human being (agent) even his involuntary actions are voluntary; and his experiencing of volition and his experiencing of will are connected pre-conditions of his actions.

Taking into closer account the topic of rationality, it could be treated as providing for the normativity. The following is a background of relevant understanding of normativity. Normativity as a general feature of philosophical approaches to a particular topic is devoted to provide and regulate the order of items which are included into it. Normative character of an approach appears when it intends to purposefully regulate items thematically covered by it. Such directing and regulating realized via generating what norms, rules, tasks, standards of an investigation under the approach ought to be. Norms condition the character of particular rules established to constitute and maintain the order. The significance of norms is not universal in general but relevant to the scope of the approach they are appropriate to constitute and regulate. At the same time within a particular investigative scope the significance of norms and their force is 'universal'. Norms obviously are not facts, they are not about 'what there is' but about 'how something ought to be'. Norms are not values but provide values (such as good and bad; right and wrong; true and false), they provide the way of evaluating and concluding about or prescribing values.

Philosophical elaborations about normativity involve both methodology of science and morality (ethics). That is why there appear different attempts of accommodating and accepting it. The discussion between P. Boghossian, C. Wright and JC Beall gives examples of such attempts. After bringing it into attention, the case of 'auto-justification' is analyzed with the aim to trace the possibility of preserving normativity consistent with relativism.

Relativism challenges normativity of philosophical elaborations. Nevertheless, that methodologically relativism is questionable and not acceptable when it is directed in general to everything at all (then relativism would turn to itself and relativize itself, thus it would reject its own generality and appears to be local), it is not avoidable in some particular fields (approaches) that involve normativity, for example, as P. Boghossian brings them [Boghossian, 2006], about morality or epistemic justification. 
The discussion between Boghossian, C. Wright [Wright, 2006]. and J.C. Beall [Beall, 2006] goes around whether some contradicting propositions can or cannot be faultless under a coherent theory. The first from the mentioned deliberators denies this while the others propose to consider some possible interpretations under the 'ordinary view of dispute of inclinations'. Contradicting propositions that are contents of opinions, tastes or inclinations can be faultless. They are asserted and maintained by their bearers. 'Ordinary view of dispute of inclinations' can be understood as a part of conceiving morality. In Wright's article the first is described as such that it is possible and often it is the case that strictly speaking excluding one another positions are rationally maintained and are not mistaken simultaneously.

Then there remains the instance of epistemic justification if it is possible to reserve faultlessness in question in this case. If it is, it would also involve the topic of truth and certainty. Beall insists that relativism under discussion can even be consistent with correspondence about truth: truthfulness of contents is due to the correspondence with the way 'the world is', but recognition of 'how it is' is relative.

To go into some further details of their discussion, let's remember that Boghossian allows coherent relativism, but not about elaborations in philosophy and in most of science or rather in methodology of science. Such relativism forbids (assertion of) absolute facts and propositions that express them, significances (values) of both facts and propositions are limited, are relative. Thus, the author would agree that morality is relative, but it cannot be relative as a topic of philosophical analysis. Let's take the mentioned limitations to be entailed by a striving to preserve normative character of philosophy and methodology of science. But we claim that even epistemic justification enters the 'ordinary view of dispute of inclinations'.

Epistemic justification concerns propositional knowledge and is problematic in all its main versions of externalist and internalist approaches (foundationalism, coherentism, reliabilism). Justification of knowledge supplies its certainty, which is essential for its status. Certainty as a feature of knowledge excludes the possibility of mistake (falsehood), doubting and lack of justification. At the same time neither knowledge no its characteristics such as justification (can come in degrees), truth (one-one relation or property, cannot come in degrees) or certainty (also one-one property, cannot come in degrees), are intended to be taken a priory, necessary etc.

If we do not separate the propositional knowledge from 'knowledge-how' and 'knowledge by acquaintance', knowledge could be understood as self-performative. Justification could be treated in terms of performative self-justification (auto-justification) when what is said cannot avoid to be accomplished. Such utterances are performative, can be done only by the 1st person; they can be about our direct experience, accomplished experience of the self. Such experience cannot be invalid; we can experience, for example percept, mistakenly (illusion) or falsely (hallucination); we can incorrectly identify experience or wrongly articulate about it; but experience evidences itself. Making such utterances does not presuppose special intuition or state of consciousness. The content of these expressions realizes itself, this supplies their certainty and justification, excludes possibility to doubt 
them. There is no need in any further tool for their justification. What is said by it is accomplished, realized; what is stated by it makes it to be done; such expression is a condition of possibility of its making (saying, realizing). Thus, each of them is always true, its content is knowledge. But, the content by itself is not necessary true, its realization is necessary true. What is stated by it could not be possible to say, if it was not the case.

Descartes' 'Cogito ergo sum' can be taken as an example of self-justification [Laktionova, 2015]. 'I exist' is not a consequence of 'I think'. They are not logical truth and are independent of each other. They are similar, according to A.J. Ayer, to pointing gestures or exclamations, they explicate implicitly obvious issues, so their deliberate expressing entails corresponding context [Ayer, 1956]. The content of such sentences does not say much. 'I exist' does not describe how I exist. The possibility of saying it is just a case; it just happened that the speaker who says it exists. It just happened that I exist; I say about it, I am justified and certain in doing it. The fact that I think is analogous. My saying 'I think' evidences for me my selfrecognition, self-consciousness; mind at once is aware of itself; my saying 'I exist' evidences for me my own existence.

Each of these statements cannot be said falsely. Any speaker sensitive to rational correct using of words is not capable to express a sentence 'I exist' or 'I think' to make a false proposition. They have performative, ostensive character. Their using accomplishes their content. Because 'I think' or 'I exist' are not descriptions, we cannot be mistaken or false when utter them. But, the remaining difficulty is that they do not say much.

Nevertheless, it seems obvious that self-justifying by their realization contents (more general, the fact that some contents work) are recognized from the 'ordinary view of dispute of inclinations'. They can play the role of foundation for epistemic justification as samples. That would preserve the normativity of philosophical analyses of epistemic justification in a transformed toward relativism way.

Will is a very old important philosophical concept, an analysis of which is very specific, if not odd, comparatively with the others (when it fruitfully proceeds in terms of criteria). This concept ('will') is going to be used to provide and clarify conditions of possibility for person of being an agent. In doing that I refer to the correspondent pieces of Wittgenstein's Tractatus and Philosophical Investigations; and to their interpretations by M. Alvarez in "Wittgenstein on Action and Will" (2009) and D. K. Levy in "Morality without Agency" (2017). Person is essentially constituted by 'powerless' will in terms of 'understanding' that is experienced during her life. Action depends on and manifests understanding by will of a personal attitude to some states of affairs. Will does not incline a person to particular desires about preferable states of affairs or actions. Will is not about states of affairs. By willing I value the world, its portions, they appear significant, important to me.

Philosophy of action, philosophy of agency, practical philosophy constitute common sphere of philosophical research, which is not reducible to ethics (philosophical discipline about how to act?; what is right and wrong? etc., it implies 
the mode of 'ought'). Moral philosophy seems to be more general area with which each of the mentioned philosophical branches can be concerned. The moral and morality do not coincide. Morality is constituted by habits, habitually acquainted practices, customary rules. Moral is rather about laws: moral laws, principles etc. In such a way moral can appear to be included to morality. In each of the mentioned philosophical disciplines a concept of 'acting person', 'agent' is unavoidable.

To sustain the proper concept of agent some conditions of possibility of personal being as an agent might be outlined. Agent is capable of acting. Acting or performing actions is realization of agency (essential potential capability to act). To allow prescribing to an agent agency, some conditions of possibility might be established. If we speak about person as agent, she cannot avoid a) being identical to itself, b) being free to act (realize agency as capacity in actual actions or conscious omitting from an action). Freedom of person as agent in terms of will, willing is the main subject of the following analyses.

M. Alvarez [Alvarez, 2017] concentrates her investigation about action and will on § 611-619 of Wittgenstein's Philosophical Investigations. Wittgenstein underlines that 'to will' cannot be directed to willing, but action is voluntary due to the personal will. The will is not controlled. A person experiences something which happens by her willing.

For Alvarez it seems crucial that confusion about these matters can be clarified by clarifying the expression "bring about by willing". Willing does not bring something to happen; but one can bring the act of willing to happen. Willing itself is a very special action, if it is an action at all: I cannot will mistakenly (fail to will) and I cannot intend or attempt to will. If the will is directed on particular action, if the will happens as striving to do something in particular, then there are some obstacles which complicate this action, otherwise, there would not have been any evidence (and (linguistically expressed) reference) of will.

So far, the notion of intention has been engaged. Understanding of intention by E. Anscombe [Anscombe, 1957], is connected, according to Alvarez, with the topic of will of Wittgenstein. Intention to do something is different from will; intention is directed on some particular rational action to obtain the needed effect (result). Attempt or try to act differs from the intention and will. Attempt can be an indicator of some difficulty or unsureness (doubt) or both about success of the intended action (of the performing an action or of achieving the results, or both). Intention and attempt can be directed to an action, to obtaining particular results by performing this action or both (to action and its results). When intention or attempt is about result, then it is rather expected. Expectation like prediction origins from rational (theoretical and practical) estimation of means and ends in a context of action. Rational evaluation of the former involves believes, evidences from previous experiences, other factors validly estimated as justificatory reasons. All the latter do not preclude from mistake or inaccuracy of the conclusion.

Success of an action is indicated by admitting successful results of an action. They might not coincide with the rationally recognized previously to action expecta- 
tions. Being aware about expectations might be or might not be accompanied by being aware about intentions and attempts to act. Attempt, intention, expectation are not causally interrelated, but may be obviously (not necessarily causally) interconnected. Each of them is not always explicitly (and even implicitly) present in every action. Not every action is intended and expected. Every action (though not always properly realized) can be approach as an attempt to this action (successful or unsuccessful). A will does not presuppose and depends on action, intention, attempt, expectation or effects of an action; but in some cases process of willing, acting, intending, trying, expecting can be obvious correspondent in not committing way.

In the "Morality without agency" (2009) D.K. Levy reconstructs ethics of L. Wittgenstein. He insists on the following important points of ethical issues sparingly present in explicit way in the legacy of Wittgenstein. Human will and independent world are isolated from each other. Will is powerless. Morality is not connected with the power to act. Nevertheless, agency involves moral challenges. So, agents are morally powerless to act, but there is a place for morality, not in terms of agency and actions, but in terms of moral understanding and response. Actions and agency are not crucial to provide account of morality.

In the early writings of Wittgenstein Levy outlines tree illustrative for his interpretation topics: "the valuelessness of facts, the unworldliness of self, and the powerlessness of will" [Levy, 2009: p. 263].

The valuelessness of facts is due to contingency of all the facts (actual and possible). Every fact is about what there is in the world. Every fact is not a value; every fact has no value. All of the valid propositions picture the portions of the world in terms of fact. A proposition about value is impossible. Ethics is about values. Propositions with ethical contents are impossible. Levy reasonably underlines that this conclusion is not about impossibility of ethics as such, but about lack of linguistic expressions of such contents. In doing so he mostly refers to $\S 6.4-6.42$ of Wittgenstein's Tractatus.

Elaborating the unworldliness of self, Levy insists that for Wittgenstein (TLP 1922: 5.631) willing and thinking ' $I$ ' is not in the world, we cannot establish ' $I$ ' in terms of facts. Identity of 'I' involves bodily physical features, describable in terms of facts, but the identity is not reduced to it; it involves not less importantly thinking and willing of ' $I$ '. The latter are not describable in terms of facts, and are not in the external world. "In this sense, the self does not exist in the world" [Levy, 2009: p. 265]. It limits the world, world's linguistic descriptions. I exists, but not in the world. Physical bodily changes might not influence any changes in thoughts and vice versa. But, let me remind that body, physically available in the world, also crucially constitutes person's identity as a whole organism. Thus, person is not reducible to its body, or mentality (thinking or will, or both; or soul etc.), but remains to be more than any comprehensible counterparts. Being the limit of, or being on the limit of the world, person is always able to overcome herself.

Levy makes relevant for Wittgenstein analogies with I. Kant's distinction between phenomenon and noumenon. This distinction can be applied to will. Then, 
we have phenomenal and noumenal will. Phenomenal will is investigated by psychology. Noumenal will is a bearer of ethical (properties or predicates, unable to be validly caught or described by linguistic expressions; as each of the latter is about something in the world).

Concerning the powerlessness of will, Levy emphasizes its central significance for the advocated by him morality (or ethics) without agency. For Wittgenstein (TLP 1922: 6.37 and the following 'rungs' or paragraphs), the only proper case for necessity is logical necessity. There is no necessity in the world. The world is not dependent in any way on my will, thus there is no necessary links between me and the world around. The concept of necessity could be treated in terms of causation, causal connections. There seems no place for any of the latter in Wittgenstein's approach, no causality even in the world. Even if realization of will was in the world (which is not), it still could not have been understood as causal effect; it would have been not necessary, but contingent.

The last deliberations could illustrate why the will is powerless: it does not change anything in the world, any facts of the world, expressible linguistically. At best will changes the limits of the world (TLP 1922: 6.43). The will can be active, but powerless regarding the world. Its actions and effects of its actions are not expanding in the world of facts, available in logically valid propositions. They are out of the world and logic, they are within ethics. Events in the world are caught by facts, states of affairs. None among events, facts, states of affairs, logically valid propositions, linguistic expressions or their samples is appropriate to be evaluated as 'good' or 'bad', or for the attaching of any other ethical characteristic.

Similar to logic, ethics is not in the world, but both of them are of available world. Logic is non-sense due to its tautological character; ethics is sense-less due to its transcendent attitude to the world. Ethics and logic are out of the world, but are transcendental, supply conditions of possibility of the world (its happenings) for 'I'.

Ethics is within the scope of personal will: person is capable of ethical understandings. Ethical understanding are of (different from those about world) 'higher meanings'. Such properties as good, bad etc. are not about the world; person (by understanding them beyond the world), his will is their source. Levy treats the previous as if person "imbues the world with the higher meanings including good and evil" and concludes "ethics requires a subject who is engaged with the world but who is not in the world" [Levy, 2009: p. 268]. Further, "One's willing seems paradoxically both redundant and necessary" [Levy, 2009: p. 268]: willing obligatory engages the world but does not control its happenings (events). Wanting and its fulfillment are logically independent.

Personal body is within the world; personal will is out of the world. Personal will relates its bearer to the world. Process of willing, act of will is not experienced by person, but involves a person, happens to person and originates from person. By willing I value the world, its portions, they appear significant, important to me, thus I am responsible for their importance. Personal will is powerless, consequences of actions are contingent. Responsibility is not causal. In such a way, "the attitude of a 
willing subject could show itself as a recognizable ethical response" [Levy, 2009: p. 271]. Activities of will are attitudes. Ethical response depends on the will, but not on action or on any influence of facts, not on any judgment fixed linguistically (none of the ethical can be expressed in language). Virtues and vices do not entail correspondent actions. Attitudes of will provide understanding of states of affairs by a person.

Ethical attitudes are internal to the actions, not to the consequences of actions. Attitudes to the facts, how one understands them are not presupposed or even anyhow influenced by these facts. Facts do not oblige me to certain definite understandings of them: "willing is ... not dependent on the states of affairs that, contingently, obtain" [Levy, 2009: p. 273]. Attitudes and will are internally related when person is not aware of his understanding, but otherwise there is no any connection.

Accepting personal will as a bearer of ethical opens skepticism about 'practical' understanding of ethical as reducible to answer the questions like "what shall one do?", "how to live?" or "what to do?", were one and his actions are treated rather instrumentally. A will is not instrumental. Will does not incline a person to particular desires about preferable states of affairs. Will is not about states of affairs. Will is not a collection of desires.

Introducing distinction between internal and external is viewed by Levy in association with essential and accidental. An action can bring externally, as its consequences, some states of affairs. But internally, action depends on and manifests understanding by will of a personal attitude to some states of affairs. In such a way 'a world' becomes to be 'my world', external accidental world becomes to be personally internally essential.

Even if I cannot control independent world which involves me, I cannot avoid being responsible for my dispositions about it. This responsibility is not of actions. Levy sees will not as freedom to act and following result of action as such that entails responsibility of an agent. Voluntarism and metaphysics of actions are not within the approach of morality (ethics) without agency (where will is not realized in action, but in ethical attitude, disposition, understanding). Ethics without agency is not consequentialist approach. It is not deontological, it does not actualize permissibility, obligation, notion of right etc.; it does not provide with a guide to actions. Thus, it is not Kantian and it is different from virtue ethics. It is wittgensteinian and actualizes personal importance of morality and philosophy as therapy more generally. Human life is not to be substituted by agents doings and what happens to him. Person is essentially constituted by 'powerless' will in terms of understanding that is experienced via different attitudes which might (but need not) be realized in wanting, responses, even formulations of goals and possible correspondent action (which brings its own consequents).

So far, will was shown to be essential feature of person. It allows seeing a person as agent without reducing the first to the last. 'Will' is more fruitful concept than 'freedom', in clarifying which it is difficult to avoid reductions and contrapositions; volition and will relate each other. Will is appropriate to constitute condition of possibility of personal being as agent. 


\section{REFERENCES}

Alvarez, M. (2017) Wittgenstein on Action and Will. In: H.-J. Glock, J. Hyman (Eds.), Companion to Wittgenstein (pp. 491-501).

Anscombe, G.E.M. (1957). Intention. Oxford: Blackwell.

Ayer, A.J. (1956). I think, therefore I am. In: A.J. Ayer, The Problem of Knowledge (pp. 44-52). London: MacMillan.

Beall, J.C. (2006). Modelling the "Ordinary View". In: P. Greenough, M.P. Lynch (Eds.), Truth and Realism (pp. 61-74). Oxford: Clarendon Press.

Boghossian, P. (2006). What is Relativism? In: P. Greenough, M. P. Lynch (Eds.), Truth and Realism (pp. 13-37), Oxford: Clarendon Press.

Dancy, J. (2004). Ethics without principles. New York: Clarendon Press, Oxford.

Hyman, J. (2015). Action, Knowledge, and Will. Oxford: Oxford University Press.

Laktionova, A. (2015). "Cogito Ergo Sum” and Philosophy of Action. [In Ukrainian]. Sententiae, 32(1), 88-99. [=Лактіонова 2015].

Laktionova, A.V. (2016). Performative Normativity in Epistemology and Ethics. Софія. Гуманітарно-релігієзнавчий вісник, 2(6), 92-95.

Levy, D.K. (2009). Morality without agency. In: E. Zamuner, D.K. Levy (Eds.), Wittgenstein's Enduring Arguments (pp. 262-280). London, New York: Routledge.

Greenough, P., Lynch, M.P. (Eds.) (2006). Truth and Realism. Oxford: Clarendon Press.

Wittgenstein, L. (1922). Tractatus Logico-Philosophicus. London: Routledge and Kegan Paul.

Wittgenstein, L. (1951). Philosophical Investigations. Oxford: Basil Blackwell.

Wright, C. (2006). Intuitionism, Realism, Relativism and Rhubarb. In: P. Greenough, M.P. Lynch (Eds.), Truth and Realism (pp. 38-60). Oxford: Clarendon Press.

Received 06.06.2021 